\title{
El campo periodístico en Chile a principios del siglo XX
}

Por Eduardo Santa Cruz A.

Hacia este período se habían creado en nuestro país las condiciones políticas, económicas, sociales y culturales para la aparición de una auténtica prensa de empresa, que es la consumación de la libertad de prensa, en el marco del pensamiento liberal que hegemonizaba ideológica y culturalmente la sociedad chilena. Entre esas condiciones citadas se encontraban el crecimiento de las ciudades y de proporción de la población urbana, el desarrollo y crecimiento del aparato educacional y la reducción del analfabetismo, el desarrollo y expansión del campo cultural, los avances tecnológicos en la imprenta y un marco legal suficientemente permisivo como para hacer atractiva la inversión de capitales en el negocio informativo, cuestión asegurada por la ley de imprenta liberal de 1872. Así, se articularon tendencias más bien universales del desarrollo moderno con las características y formas específicas de la modernización capitalista chilena, emergiendo en nuestro país en sus características básicas un mercado informativo y cultural de tipo moderno, incluyendo un plano diferenciado de desarrollo de una esfera pública plebeya y popular, desde donde se articuló la lucha por la emergencia de una cultura popular masiva que reivindicaba la plena visibilidad y legitimidad de su carta de ciudadanía, lo que se expresó en el ámbito periodístico en la llamada prensa obrera, como veremos más adelante. 2

La prensa chilena va a vivir el desarrollo de estos procesos que van a culminar con la consolidación del modelo periodístico liberal moderno, en tanto forma hegemónica de practicar el oficio, durante las dos primeras décadas del siglo veinte. Simbólicamente, el hito fundacional de la entrada del periodismo nacional en la sociedad moderna ha sido en forma relativamente consensual estimado en la fundación de El Mercurio, de Santiago, el $1^{\circ}$ de Junio de 1900. Sin embargo, como se ha recalcado recientemente 3 ello implicó un período no menor de avances y retrocesos, de cambios y rediseños de las estrategias comunicacionales en el propio caso del diario de Edwards. Un testigo y actor de esa realidad la explicaba posteriormente, poniendo el énfasis en el carácter determinante que jugó el factor económico, en términos de consolidar como hegemónica a la empresa periodística: "Con el aumento brusco de la población en las grandes ciudades, la vida se complicaba en forma peligrosa. El comercio exigía diarios de propaganda que favorecieran el intercambio de productos, y para ello era necesario que la hoja informativa penetrase a hogares de los más opuestos credos. ¡Aumentar el tiraje! ¡Contratar avisos! He ahí la orden del nuevo periodismo. Sin una vasta circulación, un diario no podía exigir avisos a precios remunerativos. Por otra parte, para obtener tiraje crecido era necesario saber interesar a un público heterogéneo y subdividido hasta el infinito. Un periodista moderno debía preguntarse antes que nada: ¿Cuál es mi público? ¿Qué lectura debo ofrecerle? Y como respuesta, debía distribuir su atención en un extenso círculo de lectores (...) El periodismo de 1900 comprendió el problema en casi la totalidad de su extensión. Lo que no calcularon bien los propietarios de publicaciones fue el sacrificio monetario que imponían las nuevas costumbres periodísticas. Aumentaron su capital, pero no en la proporción debida (...) El diario moderno no puede llenar su programa con la sola buena voluntad de la dirección y de su personal. Necesita elementos, y todavía más, reservas cuantiosas de dinero para afrontar las pérdidas de los primeros años (...) El Mercurio y El Diario llustrado dieron la pauta de lo que debería ser el diario chileno del futuro"4

\section{La transición hacia el periodismo liberal moderno}

El proceso de transformaciones que vive la prensa chilena a comienzos del siglo veinte significó una transición entre un tipo de periodismo, más ligado a la vocería y difusión de doctrinas como expresión de partidos o grupos políticamente definidos, a otro, más bien ligado a las exigencias de un mercado informativo en creciente desarrollo y expresadas fundamentalmente bajo la forma de la ampliación del círculo de lectores y la captura de publicidad. En dicho proceso es posible diferenciar dos fases, en términos generales y 
amplios. Una primera etapa que, más o menos abarca toda la primera década en que coexisten diversos tipos de diarios, en que junto a la voluntad, decisión y capital que El Mercurio pone en acción a fin de instalar exitosamente la nueva forma de hacer periodismo, permanecen dificultosamente diarios protagonistas de las últimas décadas del siglo anterior y, también, aparecen nuevos medios de vida más o menos efímera, que no son propiamente clasificables en uno u otro de los anteriores.

En esos primeros años del siglo entrante van a desaparecer cuatro diarios de importancia significativa, aunque por razones disímiles. Un caso destacable lo constituye el de La Libertad Electoral, fundada en 1886 para combatir la intervención oficial en las elecciones. Sin embargo, a pesar de este propósito determinado por la coyuntura política hay en él ciertos elementos que dicen relación con los cambios que se acercaban. Uno primero es el hecho de que La Libertad Electoral fue fundado como órgano oficioso del Partido Liberal, pero dos años más tarde, se conformó la propiedad como sociedad anónima. Si bien el diario asoma como un prototipo del medio instrumental a la difusión doctrinaria y herramienta de la lucha política, tuvo al decir de Luis Orrego Luco una segunda característica que lo hace novedoso, ya que en él la noticia comenzó a tomar (...) un lugar casi tan importante como en la (prensa) norteamericana.5 Sin embargo, su perfil dominante respondía más a la concepción decimonónica, cuestión que el propio diario dejó de manifiesto en su último número, aparecido el 31 de Diciembre de 1901 y en cuya editorial se señalaba que el Partido Liberal estaba organizando un nuevo diario que vendría a ser su sucesor.

Un segundo caso a destacar es el de La Ley, fundado el 10 de Junio de 1894, con el slogan de Diario radical. Durante toda su existencia tuvo cuatro páginas, tamaño sábana, sin fotografías ni ilustraciones y escrito a ocho columnas. Dicho diario es posible clasificarlo como uno de los mejores exponentes de difusión doctrinaria y ese juicio se puede sostener, al menos, en las siguientes características que el análisis de su estrategia periodística devela: en primer término, la mayor parte de sus contenidos incluso informativos dice relación con la política, entendida ésta como el funcionamiento del sistema de partidos y la acción del gobierno. Así, las secciones más estables son lógicamente la Editorial que va siempre en la primera página, junto a Actualidad y Notas del día, ambas incluyen casi exclusivamente temáticas como las señaladas. Una segunda cuestión es que aunque trate temas relacionados con otros aspectos de la vida social, éstos son leídos e interpretados desde la doctrina o se establece de alguna forma una relación con ésta. Por último, cabe consignar un elemento propiamente periodístico cual es el hecho de que una parte importante de los contenidos del diario tiene la forma de lo que en la época se denominaba Remitidos, es decir artículos o cartas enviadas por lectores, normalmente personalidades afines al pensamiento del diario, aunque la corriente moderna en la prensa más bien apuntaba a su desaparición y reemplazo por periodistas profesionales. Incluso lo que es presentado como mera información en el diario, muchas veces tiene dicho origen.

Si bien lo anterior constituye lo medular del diario, éste incluye otras secciones menores que tienen estabilidad a lo largo de la década y que constituyen una suerte de concesión a la vocación por la información que se está imponiendo en la época en la prensa nacional. Es interesante que ellas se ocupen de ámbitos relacionados con una creciente y masiva adhesión, como son el teatro y los espectáculos, por una parte, y los deportes, por otra. De igual forma, el diario no renuncia a la publicación de folletines. Sin embargo, desde 1905 en adelante esta práctica desaparecerá. También hay espacio para las noticias que, en forma de telegramas transcritos textualmente, vienen del extranjero o para informaciones de provincias. Según datos de Silva Castro, hacia 1908 La Ley tenía una circulación cercana a los 12.000 ejemplares diarios. Sin embargo, ello no sería suficiente para asegurar la supervivencia autónoma y dejó de aparecer el 22 de Mayo de 1910.

Un caso distinto, pero igualmente significativo lo constituyó el de La Tarde. Se trató de un vespertino que comenzó a aparecer el $1^{\circ}$ de Enero de 1897, fundado por los hermanos Galo y Alfredo Irarrázaval Zañartu: "Era su intención hacer un nuevo tipo de periodismo, en que la ligereza de la redacción y la gracia de la forma pudieran combinarse con altivas campañas de orden político"6. Entre estas últimas destacaron las relacionadas con la política exterior del gobierno de Errázuriz Echaurren, acerca de los problemas limítrofes con Argentina y Perú y la 
defensa del papel moneda frente al patrón oro, en el ámbito económico. Sin embargo, la experiencia estrictamente periodística de sus fundadores los llevó a darle al diario tanto un estilo más cercano a lo informativo, así como diversificar sus contenidos en la perspectiva de ampliar su radio de circulación7. Según el testimonio de uno de ellos, La Tarde era: "...nuevo como estilo, sin "remitidos" ni editoriales de levita y sombrero de ocho luces y, en cambio, lleno de artículos, crónicas, reportajes e instantáneas, ágiles, livianos e informaciones en que los personajes aparecían tal cual, es decir, vivos, hablando, charlando (...) "La Tarde" era, pues, una atrevida innovación que, a pesar de lo limitado de sus recursos venía a transformar el periodismo de que había sido modelo o patrón el ahuesado "Ferrocarril"8

Cabe destacar la pretensión innovadora y reformadora de los estilos y las rutinas imperantes, aunque en La Tarde y sus impulsores no estaban presentes ni el poder económico suficiente ni la voluntad empresarial capaz de crear una estructura administrativa y orgánica relativamente estable en el tiempo como para cumplir con aquella. Por el contrario, para las elecciones presidenciales de 1901 disputadas entre Germán Riesco y Pedro Montt se produjo una división entre los miembros del diario los hermanos Irarrázaval lo vendieron a un personaje de vocación mucho más marcadamente empresarial como lo era el propietario de El Chileno, Enrique Delpiano, hasta dejar de circular el 15 de Diciembre de 1903.

Sin embargo, el caso más importante en lo que se refiere a la desaparición de diarios provenientes del siglo anterior es el de El Ferrocarril. Competencia directa que El Mercurio debía vencer en su empeño para consolidarse como el principal diario nacional, El Ferrocarril entró al nuevo siglo con la ventaja de la hegemonía que le daban sus casi cinco décadas de existencia. Si El Ferrocarril había sido en muchos aspectos el introductor de la prensa liberal moderna9, El Mercurio llegaría a constituirse en su modelo y paradigma. En otras palabras, El Mercurio venía a hacer lo mismo que El Ferrocarril hiciera durante 45 años, pero con el agregado de contar con mayores recursos; una administración empresarial racionalizada y eficiente; la base tecnológica más moderna que existía a la fecha y, en lo periodístico, el desarrollo de las características informativas, por el perfeccionamiento de las técnicas y géneros, a partir de la plena profesionalización de la actividad10. Sin embargo, no abandonaría el terreno sin luchar. Por el contrario, en sus últimos años se llevó a cabo una importante transformación de la estructura del diario, en la perspectiva de ofrecer un formato y estilo más acorde a los de la prensa informativa. Ello ocurre con la edición del 12 de Octubre de 1910, en la cual se produce un cambio de formato y de la estructura del diario bastante radical. Por una parte, el tamaño se reduce al luego llamado Mercurio, las páginas aumentan a ocho y a veces doce páginas y se inauguran secciones estables dedicadas a la información breve y amplia.

Entre las nuevas secciones cabe destacar, al menos, las siguientes: Lectura para la familia, la cual ocupaba una o dos páginas completas e incorporaba la subsección El Día Social, dedicada a la vida social; otra, primero denominada Diversiones Públicas y luego, simplemente Teatros, dedicada a la cartelera teatral, de cine y espectáculos, con notas breves de crítica y comentarios; además se incluía el Obituario, una Miscelánea Doméstica y un Folletín. Por otra parte, se inauguró la sección Notas Populares, a la que se le dedicaban dos páginas completas, y la cual incluía también otras subsecciones como Sociedades, en la que figuraban las citaciones a reunión y las actas de ellas de mutuales, sindicatos y otras instituciones u organismos sociales; también, la ya tradicional Sport, pero ahora con más espacio y una información más amplia sobre el deporte y la Hípica. Sin embargo, la más llamativa es la denominada Policía, que recopilaba una cantidad no menor de noticias de ese ámbito, muchas de ellas tituladas de manera destacada11. Otras secciones permanentes fueron Noticias telegráficas, que incluía informaciones del extranjero y regiones y que ocupaba una o dos páginas y Comercio e Industrias, que en un espacio similar contenía información comercial y financiera variada, así como avisos comerciales. En 1911, al aumentarse el número total de páginas a doce, se incluyó la sección Actualidades, que ocupaba tres de aquellas. Cabe consignar finalmente que existían otras dos secciones que ocupaban una página cada una, Sección Judicial, con informaciones oficiales del funcionamiento de los Tribunales de Justicia y Administración Pública, donde ahora aparecían un tanto recluídas las noticias ministeriales y de gobierno y las Actas de sesiones del Senado y la Cámara de Diputados. Asimismo, esta reformulación completa del diario significó que El Ferrocarril se 
incorporara también al mundo de la imagen, vía publicación de fotografías, especialmente en su primera página, a contar de Diciembre de 1910.12 Lo anterior demuestra que existió un esfuerzo importante por modernizar el diario y colocarlo en condiciones de competir en el mercado. Sin embargo, es llamativo el hecho de que, al parecer ello no tuvo una respuesta en términos de capturar publicidad. A pesar del aumento del número de páginas, la cantidad de avisos es bastante menor y aparece repartida en forma de pequeños anuncios en distintas páginas, siendo de hecho menor en cantidad a la que el diario tenía, por ejemplo, en 1907. Es probable que tampoco haya habido de parte de sus propietarios el capital suficiente o la voluntad de absorber pérdidas durante mucho tiempo13.

Así como es posible situar un tanto simbólicamente la entrada del periodismo liberal moderno en Chile con la fundación de El Mercurio, de Santiago, en 1900, la desaparición de El Ferrocarril en 1911 vino tal vez a confirmar también de manera simbólica el triunfo de la estrategia comunicacional que aquel encarnaba y de la empresa periodística, en tanto su soporte orgánico y empresarial. Sin embargo, ello no significó que durante esa primera década del siglo veinte no surgieran una serie de otras iniciativas, en términos de fundación de diarios que respondían más bien al modelo de prensa doctrinaria, guiadas por estrategias de carácter más coyuntural y que se afirmaban más bien en el esfuerzo y la voluntad de sus fundadores y colaboradores, antes que en los recursos económicos cuantiosos que podían aportar14. Junto a ellos y para aumentar la diversidad de la oferta es necesario mencionar a El Chileno15 y El Diario Popular, el primero consolidado en esta primera década como un proyecto empresarial que su propietario, Enrique Delpiano, quiso convertir sin mayor éxito en una importante cadena nacional de periódicos y el segundo, como un instrumento de la Iglesia Católica para llegar con su particular lectura del acontecer nacional fundamentalmente a sectores populares. En este diario comenzó sus labores periodísticas el escritor y más tarde Premio Nacional de Literatura, Fernando Santiván, el cual lo definió de la siguiente forma: "El Diario Popular, como el antiguo Chileno, se vendía a la mitad del precio de los otros diarios, es decir, a dos centavos y medio, y cultivaba el estilo sensacionalista, la crónica policial y la noticia de carácter espeluznante"16

Se trató de un diario de cuatro páginas, sin mayor uso de fotografías o ilustraciones, que reproducía en gran medida el ya probado modelo y estilo desarrollado por El Chileno en la década anterior. Si bien el diario no tenía dependencia directa y orgánica, en tanto vocero oficial, de la Iglesia Católica, la presencia de ésta era muy concreta, a través de ciertos prelados destacados por su labor periodística en la época. Entre ellos el Presbítero y luego Obispo, Rafael Edwards. Junto a él se desempeña como director del diario en sus primeros años, Carlos Casanueva Opazo, más tarde Rector de la Universidad Católica y Arzobispo de Santiago y, al decir de Santiván, desempeñaba su labor de director del medio plenamente, dedicándole gran parte de las horas del día17.

En suma, a lo largo de la primera década del siglo veinte se vive un cuadro complejo en la prensa nacional, cuestión que da cuenta del profundo proceso de reconfiguración del propio campo, por la irrupción, no sin contradicciones, de un modelo de prensa más acorde con los patrones universales que la modernización liberal estaba imponiendo y que estaban rearticulando también la cultura y vida cotidiana de la sociedad chilena. Dicho proceso discurre relacionadamente con la diversificación del campo periodístico y la aparición de nuevos formatos y géneros, así como con la irrupción de nuevos medios como el cine y, en general, con una nueva percepción del tiempo y el espacio, de la ciudad, de la presencia cada vez más importantes de nuevos actores sociales y de la cuestión social, etc. por ello, es que podemos afirmar que para la prensa nacional, la primera década del siglo veinte muestra más bien un perfil claramente de transición entre un periodismo todavía tributario de los cánones decimonónicos en retirada y un tipo de prensa que caracterizó buena parte del desarrollo del campo en el siglo veinte y que se hace crecientemente predominante.

\section{Avisos, noticias y fotografías}

Es posible sostener que en la segunda década del siglo veinte el modelo informativo ya se consolida como dominante en la prensa nacional. Como veremos, ello significó que otras iniciativas de fundación de diarios, incluso con propósitos de difusión doctrinaria se 
adscribieron a la nueva concepción de la prensa, lo cual vino a demostrar que la prensa informativa moderna operaba sobre una matriz suficientemente maleable y flexible como para vehicular diferentes tipos de contenidos. Es posible que la verificación más rotunda del juicio anterior lo encontramos en la declaración explícita que formuló La Nación, al aparecer públicamente en 1917, al señalar: "Desde la fecha, a quince años de distancia (sic), en que el lanzamiento de El Mercurio vino a romper todos los moldes del periodismo chileno, revolucionando hasta sus cimientos los procedimientos de la prensa nacional, el público se ha convertido en un intenso apreciador de la forma y métodos con que cada diario lo sirve. En estas condiciones, al dar a luz el primer número de La Nación, nada podemos decir de nuevo, sobre la materia, a nuestros lectores. 18

Es a fines de 1902 cuando su propietario le imprime a El Mercurio un giro que resultaría decisivo y que le significó fuertes inversiones. Desde su instalación en Compañía y Morandé, donde funcionó por décadas, hasta la reorganización y modernización de los sistemas de producción, administración y distribución del diario. Igualmente, convirtió a El Mercurio en un matutino y el 15 de Noviembre de ese año comenzó a publicar una segunda edición con el nombre de Las Ultimas Noticias de El Mercurio, de carácter vespertino. Este contaba con diez páginas, en el mismo formato de la edición matutina y se vendía a cinco centavos. Ambas ediciones eran del mismo diario, ya que compartían director y personal. Dicha situación se mantuvo hasta 1915, en que Las Ultimas Noticias comenzó a funcionar como un medio aparte dentro de la misma empresa. Concluyen los citados Bernedo y Arriagada señalando que El Mercurio recién logró posicionar su propuesta periodística y empresarial hacia fines de 1904 y, ello, sobre la base de una dura competencia, en la cual venció gracias a que su proyecto: " ...concibió a El Mercurio desde una lógica empresarial, donde la generación de utilidades en un plazo razonable, la inversión en nuevas tecnologías y la aplicación de estrategias eficientes de ventas y distribución jugaban un rol determinante; que en lo concerniente a su administración, organizó cuadros gerenciales que, además de sus conocimientos y aptitudes administrativas, tenían una visión muy completa del ejercicio periodístico; y que introdujo la concepción de que el producto que El Mercurio vendía era "información" y, en consecuencia, contrató periodistas profesionales, a tiempo completo, con capacidad de reportear las noticias..."19

Como se ha señalado, el otro diario que aparece a comienzos de siglo y que también ocupa un lugar importante en la transformación de la prensa nacional, es El Diario Ilustrado. En lo propiamente periodístico, es conocido el hecho de haber introducido el sistema de fotograbado, lo cual le permitió ofrecer la novedad de una amplia cobertura fotográfica.. Sin embargo, para efectos de este análisis pareciera necesario remarcar también algunos otros aspectos, que dicen relación con la organización y estructura empresarial del diario. Fue fundado y dirigido por Ricardo Salas Edwards y apareció su primer número el 31 de Marzo de 1902. Es el trabajo desarrollado por su segundo director, Misael Correa Pastene, el que es considerado por autores como Silva Castro y otros contemporáneos como el propio Santiván, en las obras citadas, como aquel que logró asentar la publicación sobre una base popular masiva. En ese sentido, habría jugado un papel importante el desarrollo de campañas de denuncia de problemas sociales, de corrupción o derroche administrativo, etc.: "A la información, generalmente en forma de rápida entrevista, acompañaba el grabado de sucios conventillos, de calles cubiertas de basuras, de garitos allanados en la correría nocturna de los agentes de la autoridad. Y cuando no bastaba el grabado fotográfico, venía también a pelo la caricatura, generalmente ampliada hasta lo literario con la leyenda intencionada y punzante"20

La dirección de Correa Pastene coincidió con un cambio fundamental que vivió el diario, cuando en 1908 la propiedad pasó de las manos unipersonales de Salas Edwards a las de una sociedad comercial formada por Joaquín Echeñique y los hermanos Alberto y Nicolás González Errázuriz. La consolidación del modelo empresarial que le servía de soporte se produjo en 1920 cuando éstos transfirieron la propiedad a la Sociedad Periodística de Chile, presidida entonces por Francisco Hunneus Gana. El elemento gráfico no constituía el único factor al que le podía atribuir el éxito del medio. Junto a él, existió preocupación por lo literario, a través de un suplemento especial, el desarrollo de secciones específicas, entre las cuales destacó rápidamente la de Deportes, etc. 
Al comenzar la década de 1910 la situación de privilegio de El Mercurio y El Diario llustrado estaba suficientemente asentada. Sin embargo, ello no implicó que durante la década que se iniciaba desapareciera la iniciativa de grupos ligados a partidos políticos en orden a fundar nuevos diarios con una visión más bien instrumental de difusión doctrinaria o de herramienta para la lucha política contingente. Lo distinto, con respecto al período anterior es que dichos medios van a asumir de manera significativa elementos estructurales, en lo periodístico, del modelo informativo. En ese sentido, es posible mencionar al menos cuatro experiencias significativas, ya que se trata de diarios con una clara y definida posición política. En primer término, está el caso de La Unión. Aunque se presentó como la edición santiaguina de su homónimo de Valparaíso, pertenecía al Arzobispado de Santiago y apareció por primera vez el 9 de Octubre de 1906, es decir, circuló durante tres años en forma simultánea con El Diario Popular, antes mencionado y también propiedad de la Iglesia Católica. Ello significó, como veremos, que compartieron colaboradores, comenzando por quien ejercía las funciones de dirección general del medio, el entonces Presbítero y luego Arzobispo, Carlos Casanueva. La Unión vino a suceder en la capital a El Porvenir y lo hizo con el propósito de competir directamente con los diarios de mayor circulación: "Los propietarios de El Porvenir, con esa sutileza de percepción que caracteriza a los directores de la Iglesia Católica, comprendieron que había pasado el tiempo de los densos editoriales y de las graves polémicas religiosas (...) Había que "remozarse o morir". Y se renovaban (...) Fue aquella una época de ruda transición para el periodismo antiguo. "El Porvenir", diario de la Curia, comenzó por cambiar su nombre por el de "La Unión". Pero eso no bastaba; era preciso aumentar las páginas a diez, a veinte, a treinta. Se requerían nuevas rotativas, rápidas, diligentes, que vomitaran decenas de miles de diarios en pocas horas. Los talleres de tipografía se cambiaron por linotipias"21 La Unión asumió así plenamente los rasgos periodísticos fundamentales del modelo informativo: secciones especializadas, abundante publicidad y avisos clasificados, una página editorial para las columnas y artículos de opinión, uso de la fotografía, especialmente en la portada y el formato mercurio, que estaba comenzando, no casualmente a ser llamado standard. La Unión, de Santiago, circuló hasta el $1^{\circ}$ de Agosto de 1920.

Un segundo caso digno de ser destacado en la misma dirección proviene del campo del pensamiento liberal. Se trata de La Mañana, aparecida a la luz pública el 17 de Octubre de 1909. Si bien La Mañana pretendió desarrollar un periodismo de rasgos informativos, no tuvo en sus propietarios la voluntad o la opción de desarrollar propiamente una empresa periodística. En ellos, según señala Silva Castro, seguía presente la visión de un medio de combate ideológico y sus vocaciones empresariales, se enrumbaban más bien en otras direcciones. Así, el diario subsistió algunos años, hasta el 26 de febrero de 1916, pero sufriendo numerosos cambios en su propiedad y dirección. De hecho, es posible considerar a La Mañana como una suerte de antecesor de La Nación, donde encontraremos luego varios de sus colaboradores, así como incluso su maquinaria de imprenta. En todo caso, el sello doctrinario que mantuvo La Mañana, de combate encarnizado, no era para hacerse capitalista, al decir de Emilio Rodríguez Mendoza22.

Otro caso es el de La Opinión. Este diario aparece el 18 de Abril de 1915 y es considerado como un vocero de la Unión Nacionalista, que pretendió distanciarse y diferenciarse de los partidos, a partir de la lectura profundamente crítica del régimen parlamentario y en especial de la actividad de aquellos23. En ello, jugó un papel importante el diario La Opinión. Su fundador y director-propietario fue Tancredo Pinochet Le Brun.. Al decir de Silva Castro era un diario con poquísimas noticias y mucho comentario de los hechos del día.24. En el período en que el diario perteneció a Pinochet desarrolló intensas y polémicas campañas políticas de saneamiento administrativo y, según Silva Castro, algunos días tuvo la más alta circulación de Chile.25. Dejó de aparecer el 14 de Agosto de 1920. Si bien el juicio de Silva Castro apunta a colocar a este diario en el ámbito de los medios más bien doctrinarios, un análisis de su estructura obliga a introducir matices, al menos, a dicho aserto. Especialmente en el período en que es dirigido por Pinochet Le Brun constaba de ocho páginas a seis columnas y era de carácter vespertino. Su portada o primera página estaba compuesta normalmente de noticias de actualidad nacional con titulares impresos en tipografía destacada y de artículos relacionados con alguna de las campañas de opinión pública que, efectivamente, constituían un aspecto medular de la publicación26. 
Sin embargo, no sólo ocuparon sus páginas las denuncias y las polémicas, también es posible encontrar campañas más propositivas. En esa dirección, un tópico recurrente y privilegiado lo constituyó todo lo relacionado con el desarrollo de la industria nacional.27 Sin embargo, el diario no se agotaba en materiales como los descritos. También tenía secciones estables que decían relación con otros ámbitos de la vida social y en las cuales predominaban los contenidos informativos. Es el caso de la sección Teatros, en la cual se incluían notas breves y la cartelera de teatro, cine y espectáculos en general o de la sección Deportes. Igualmente las noticias policiales no están ausentes, aún cuando se les incluye junto a otras de actualidad nacional, sin agruparlas en una sección específica. Por otro lado, al igual como ocurría con la mayor parte de los diarios, La Opinión debía entregar una serie de servicios informativos que decían relación con intereses particulares de diversos sectores de público. Ellos se incluían en la sección Memorandum (nombre más bien genérico, ya que lo encontramos reiterado en diversos diarios para reunir este tipo de informaciones), en la cual aparecían informaciones comerciales y financieras, turnos judiciales y de médicos y boticas, remates, movimiento de barcos, precios de productos agrícolas, etc. De la misma manera, encontramos una Guía Profesional. Al igual como ocurrió con toda la prensa nacional del período, el impacto producido por la Primera Guerra Mundial significó que cotidianamente se le dedicara un espacio destacado en la sección Noticias Extranjeras. En este ámbito vemos desplegada a la manera del periodismo moderno la información breve, pero lo más inmediata que las condiciones de la época permitían.

Lo que el diario no contempla, probablemente por carencia de recursos más que por opción, es el uso de la imagen, ya sea en la forma de ilustraciones o fotografías, cuestión que ya para mediados de la década de los '10 era un elemento imprescindible de diarios como El Mercurio - El Diario Ilustrado y luego La Nación. Solamente la encontramos de manera circunstancial en algunos de los avisos económicos. En este último plano, el hecho de que el diario tuviera no solamente una posición ideológica y política explícita, sino que más aún actuara como vocero oficioso de un grupo importante de opinión en ese sentido, no fue obstáculo para que intentara el desarrollo de una estrategia comercial similar a la de otros diarios. Así, cada edición consultaba dos páginas completas de avisos comerciales de muy variada índole, todos los que se presentaban con recuadros y viñetas que los destacaban y separaban visualmente, incluyendo como se dijo en algunos casos ilustraciones o fotografías. Además de ello, aparecían también en una extensión normalmente de media página de avisos económicos clasificados. En definitiva, ante La Opinión nos encontramos más bien frente a un tipo de diario que desarrolla un cierto modelo híbrido, que contempla rasgos propios de los diarios más propiamente doctrinarios pero, a la vez, incorporando varios elementos que lo acercan al modelo informativo moderno. Lo también interesante es que las noticias y comentarios relacionados con lo estrictamente político partidario es más bien minoritario. El énfasis está puesto en temas económico-sociales y en la vivencia cotidiana, desde la perspectiva de una sociedad en crisis.

Por último, en esta revisión de nuevos diarios ligados más o menos estrechamente a grupos partidarios es necesario destacar el hecho de que, poco después de desaparecido La Ley, se realiza un nuevo intento por publicar un diario que fuera órgano del Radicalismo. Es el caso de La Razón, que aparece el 16 de Junio de 1912 y al decir de Santiván: "Se trata de un periódico que se inscribe en la línea del radicalismo progresista de Valentín Letelier: le cede dos páginas a la semana al partido democrático; uno de sus temas reiterados es la educación de los obreros; apoya y aplaude las escuelas nocturnas creadas por los estudiantes para este fin, "instruyamos al pueblo!", dice un gran titular de primera plana. Se trata de un periódico en que se articulan sectores medios progresistas, junto al movimiento estudiantil y la intelectualidad bohemia y antioligárquica...Abraham Konig, Armando Quezada y el líder de la FECH, Alejandro Quezada, son algunos de los colaboradores más asiduos; el periódico abre también sus páginas a líderes del partido democrático o a líderes obreros como Luis Emilio Recabarren. Colaboran también destacados literatos como Víctor Domingo Silva, Pedro A. González, Antonio Bórquez Solar, Carlos Pezoa Véliz y Pablo de Rokha"28

Subercaseaux también señala que en el diario se le dedica una página al tema femenino y se defiende la concesión de voto para la mujer. Es importante señalar que La Razón establece un matiz de diferenciación con respecto a La Ley y dice relación con el hecho de que las 
condiciones del país han cambiado y le dan un nuevo carácter a la lucha ideológica. La lucha ideológica puramente doctrinaria contra los católico-conservadores ya no es sostenible en la segunda década. De por medio están la explosión de hecho de la cuestión social, la extendida sensación de crisis nacional que se expresa en los llamados ensayistas del Centenario, el propio proceso vivido al interior del Radicalismo, en términos de la aparición de un sector crítico que se hace cada vez más numeroso, etc. Dicho de otro modo, la lucha política e ideológica se ha desplazado de lo meramente doctrinal a lo económico-social. Sin embargo, el diario era nada más que el producto del esfuerzo monetario de algunas personas, es decir, no generó una estructura institucional y empresarial adecuada para competir en un mercado de prensa cada vez más consolidado y, debido a ello, no fue capaz de enfrentar la competencia de los diarios grandes de la capital, sustentados en un fuerte capital y organizados en tanto que empresas periodísticas y dejó de circular el 22 de Julio de 1914.

Hacia el final de la década de los años '10 hace su ingreso al mercado de la prensa nacional un nuevo proyecto que va a expresar de una manera comercial y periodísticamente exitosa la ductibilidad y maleabilidad del modelo informativo. Nos referimos a la fundación de La Nación en 1917. Desde ya, fue el único de los medios de prensa surgidos en el período que pudo competir con cierto éxito con los llamados diarios grandes: El Mercurio y El Diario Ilustrado y lograr una consolidación tal que le permitiera trascender a las condiciones coyunturales en que fue fundado. Las condiciones político-sociales que rodearon a la aparición de La Nación eran propicias para que éste adquiriera el rasgo de medio instrumental en función de una coyuntura y unos intereses políticos específicos. En efecto, su socio más destacado, E. Yañez no solamente era uno de los principales líderes dentro de las filas liberales, sino abiertamente un aspirante a las elecciones presidenciales en 1920. Sin embargo, al decir de Silva Castro, sus propietarios: "...no quisieron publicar un diario meramente político y estudiaron el asunto hasta en sus menores detalles a fin de hacer un diario que sobreviviera a la campaña presidencial inmediata y que compartiese, si era posible, las posiciones conquistadas por El Mercurio"29

Más aún, en la editorial de ese primer número titulada Nuestro Diario se explicita en detalle el propósito de realizar la pretensión de la prensa informativa liberal moderna, es decir, la delicada operación de relegar la opinión a las columnas editoriales, preservando para el resto del diario contenidos preponderamente informativos y noticiosos. La Nación se limitó a proclamar en la editorial ya mencionada que su línea opinante y doctrinaria se reduciría a reflejar con elevación de espíritu e imparcialidad el sentimiento liberal del país, destacando el hecho de que estaba desligado de todo compromiso con la dirección de los partidos políticos y sin pretender representarlos. Por otro lado, se establecía de manera explícita que el diario se dirigía a la opinión ilustrada del país.. De este modo, el diario dejó establecidas algunas características básicas de su diseño estratégico en términos comunicacionales. Precisó un territorio o un espacio ideológico-cultural, configurando con él un estilo periodístico y una pretensión comercial y empresarial. En este último aspecto las cosas no deben haber sido fáciles, dada la dura competencia que ya existía en el emergente mercado informativo nacional. Al decir de Fernando Santiván, La Nación habría sido salvada únicamente por la visión certera de uno de sus propietarios (refiriéndose naturalmente a Eliodoro Yañez), que no escatimó medios para proporcionarle recursos.30 Lo anterior, a pesar de que el diario dedicaba buena parte de su espacio a la publicidad. De hecho, entre 1917 y 1919 tenía dos páginas completas de avisos comerciales, sin contar otra más de avisos clasificados, una guía profesional de alrededor de media página y avisos dispersos que se publicaban en las otras páginas, de ediciones que oscilaban entre las 14 y 16 páginas en total.

En lo estrictamente periodístico, La Nación plantea en su número inicial, como ya vimos, de manera explícita su reconocimiento al rol ya hegemónico de El Mercurio, sobre todo en cuanto a la consolidación de un modelo periodístico. Sin embargo, al interior del modelo al cual se subordinaba tan claramente, La Nación mostró en estos primeros años de existencia, al menos, tres características que le permitían ciertos elementos diferenciadores de su perfil y, que a la vez, se constituían en factores de competitividad en el mercado. En su primer número ya se anuncia que el diario ofrecía un servicio noticioso exclusivo a sus lectores. Se trataba de un convenio establecido con La Nación, de Buenos Aires y con la Agencia United Press, de Nueva York, con el objetivo de entregar la más amplia cobertura noticiosa del 
ámbito internacional, por entonces prácticamente copado por el desarrollo de la Primera Guerra Mundial, la cual estaba ya en su tercer año y la que había concitado gran interés y atención del público chileno, que la seguía a través de las informaciones periodísticas. De hecho, cada edición del diario le entregaba no menos de dos páginas completas en la sección Informaciones del Extranjero.

En segundo término, el diario logra reunir un grupo de periodistas y colaboradores de alta calificación y, especialmente, con probada experiencia anterior. Como lo señala el número inicial hubo en este aspecto una intencionalidad evidente en atraer un personal elegido con la más delicada atención entre los buenos elementos con que cuenta el periodismo nacional. Por último, junto al espacio dedicado a las noticias de carácter internacional, La Nación le va a dedicar también una atención creciente a los Deportes y la Hípica, no sólo creando secciones específicas y claramente destacadas, sino que concediéndole cada vez más espacio en sus páginas. Con ello, el diario adquiere un rasgo que lo caracteriza hasta la actualidad. Sin embargo, no debe entenderse que lo anterior constituía una exclusividad o la demostración de algún tipo de originalidad en la prensa nacional. Por el contrario, pareciera que dichas secciones más bien se convirtieron en espacios de competencia, especialmente con El Mercurio. Si observamos ambos diarios, por ejemplo entre 1917 y 1919, podemos ver que en el caso de las noticias internacionales La Nación releva como diferencia específica a su favor en el primer número, el espacio que les dedica y la cobertura de servicios informativos provenientes del exterior. A la vuelta de un par de años, El Mercurio presenta un espacio similar o mayor e incluso una diagramación de página similar.

Por su lado, en el caso del Deporte y la Hípica, El Mercurio tenía hacía ya varios años, secciones especializadas que ocupaban una página cada una, especialmente los días lunes, en que se entregaba toda la información de la actividad dominical y normalmente acompañada de fotografías. Al nacer, La Nación le dedicó una página compartida por ambas secciones y en 1919 cada sección tenía una página propia con presentación gráfica y cantidad y tipo de informaciones similares a las de El Mercurio. Al parecer, dicha competencia llevó a El Mercurio a que a fines de 1920 editara por un corto período un suplemento especial llamado Deportes y Deportistas, que circulaba los días lunes. Sin embargo, sería La Nación la que años más tarde introduciría de manera permanente e ininterrumpida hasta hoy la circulación de un suplemento deportivo. En síntesis, los primeros años de La Nación nos muestran efectivamente el intento de desarrollar no un instrumento efímero de difusión doctrinaria o de factor interviniente en una coyuntura política, sino que una empresa periodística de cuño moderno, es decir, que elabora un producto noticioso dirigido hacia un mercado en el cual ya existe una fuerte competencia y para lo cual estructura un equipo profesional ad hoc, así como determinadas estrategias comerciales y periodísticas. El caso de La Nación nos habla también de la consolidación de un mercado informativo y de un modelo periodístico hegemónico hacia la segunda década del siglo veinte en nuestro país.

En definitiva, la revisión llevada a cabo a lo largo de este texto nos lleva a concluir que el modelo de prensa informativa moderna, basado en la empresa periodística logró su plena consolidación en nuestro país hacia los años '10 del siglo pasado. En un proceso complejo se fue imponiendo, al menos, por dos vías: por una parte, desplazando a la prensa más bien concebida como instrumento, más o menos coyuntural, de grupos políticos o ideológicos y a veces coincidente con ello, a diarios que no tuvieran un fuerte capital u organización empresarial como base. Por otra parte, y tal vez de manera mucho más trascendente en el tiempo, su hegemonía se instaló justamente en la medida en que pudo convertirse en un modelo, es decir, en una cierta matriz acerca de cómo se hacen los diarios, es decir, naturalizándose y generando un sentido común profesional, que estaba en armonía y relación con un sentido común masivo que también se fue sedimentando, en términos del rol y papel de la prensa en la sociedad.

\section{Las voces desde abajo: la prensa obrera}

Sin embargo, no quedaría completa una mirada al cuadro que presenta la prensa nacional en las primeras dos décadas del siglo veinte sin dedicar un espacio al emergente escenario comunicacional y cultural del que forma parte la llamada prensa obrera. Como señalamos en 
otro texto, ella forma parte de un espacio público plebeyo y popular que se va constituyendo desde finales del siglo XIX y en el cual convergen diversas formas comunicacionales y culturales 31 . En lo específico, la prensa obrera surge como herramienta vital para la difusión de proyectos ideológicos que se van configurando desde la propia práctica de constitución del movimiento sindical y popular, así como instrumento de organización de éste y de contestación al proceso de transformación de la prensa liberal moderna. Dicho de otra forma, surge en el seno mismo y al calor de la lucha del movimiento obrero y popular por su propia existencia y crecimiento. Es decir, dicha prensa vive las vicisitudes de un sujeto social que se está constituyendo, en buena medida, al margen y generalmente en contra de lo establecido y al cual éste no le confiere legitimidad como actor social y cuyos discursos y acciones van a ser normalmente vistos como un peligro y una amenaza.

A pesar de los obstáculos y dificultades provenientes de los escasos recursos económicos o de la represión gubernamental, el número de periódicos no será menor e irá creciendo sostenidamente hacia 1920. Al respecto, se puede señalar que entre 1900 y 1910 se fundaron un promedio de dos publicaciones anualmente; entre 1911 y 1915 se fundaron 24 en total y, entre 1916 y 1926, la cifra llega a 139, con un promedio de casi 14 al año32. En todo caso, Arias puntualiza que se trataba de: "...publicaciones que dicen ser eventuales, quincenales 0 semanales, pero en la práctica son de espaciada aparición y escasa regularidad. Son pocas las publicaciones diarias o que se imprimen durante muchos años o que alcanzan gran cantidad de números. Sobre el tiraje no tenemos datos, pero es de suponer que en la mayoría fue pequeño"33 En general, los periódicos obreros pueden clasificarse de acuerdo a los grandes proyectos ideológicos o doctrinarios que están articulando la emergencia política o sindical de las organizaciones populares. De esta forma, Arias señala la existencia de diarios de orientación socialista, entre los cuales destaca especialmente El Despertar de los Trabajadores, fundado por Luis E. Recabarren y editado en Iquique entre 1912 y 1927 . Esta publicación fue mucho más que un diario; de hecho, se constituyó en un foco de actividad sindical, política y cultural de las organizaciones proletarias de la zona. En su local se realizaban charlas y conferencias; funciones de teatro y veladas culturales; concursos literarios y de poesía. Allí también funcionaron el Partido Obrero Socialista, fundado en 1912 y la Sección iquiqueña de la Federación Obrera de Chile (FOCH). 34

Por otra parte, existieron los diarios de orientación anarquista, se pueden mencionar por su importancia a El Surco, de Iquique, que circuló entre 1917 y 1921 y La Batalla, de Santiago, publicado entre 1912 y 1916 . También existieron publicaciones ligadas al Partido Demócrata, como El Proletario, de Tocopilla (1904-1935) y La Voz del Obrero, de Taltal (1902-1917), ambos, en todo caso, fundados por Recabarren, entonces militante de dicho partido. Menos conocidos son los casos que Arias califica como prensa sindical de carácter social-cristiano, como El Sindicalista, de Santiago (1918-1925) y un tipo de periódicos que califica de sindical independiente, por cuanto no se identificaban con ninguna corriente ideológica en particular. Por otra parte, la prensa obrera se caracterizaba por contenidos de fuerte oposición y crítica al sistema social y por su actitud contestataria y rupturista frente a éste. Con respecto a su financiamiento, éste era muy precario ya que los fondos necesarios provienen de la venta, erogaciones voluntarias de los lectores y aportes de las organizaciones de los trabajadores, puesto que, prácticamente, no tienen avisos publicitarios. El sostenimiento de los órganos de prensa se constituye para los trabajadores en una demostración del grado de conciencia alcanzado y de la decisión y voluntad de organización y acción por sus intereses. Dicho de otra forma, la pura capacidad de existir y sobrevivir es ya visto como una forma de enfrentarse al sistema de prensa oficial, cuestión que aparece claramente en Recabarren: "La prensa obrera debe ser la preferida por vosotros, porque ella os proporciona lectura sana y provechosa para vuestros anhelos (...) El trabajador que prefiere comprar un periódico burgués, de esos que adulan a los salitreros y autoridades, se hace un grave daño porque así da vida al enemigo"35

Es decir, la prensa obrera no funciona en un compartimiento estanco, autárquico y aislado con respecto a la prensa nacional en su conjunto. Lo que ocurría era que no competía con la prensa oficial, en términos de mercado, sino que la enfrentaba doctrinaria e ideológicamente, intentando disputarle los lectores en la masa popular. Dicha confrontación a veces era explícita; así ocurrió, por ejemplo a principios de 1913 cuando El Mercurio publica 
un artículo contra la obra de agitadores que aprovechándose del pueblo (calificado como un buen niño), lo explotan y le predican la reivindicación por la violencia y la anarquía. Ello motivó una respuesta directa de Recabarren en los siguientes términos: "La llamada prensa seria baja hasta la mentira ignominiosa y a la definición inconsulta y cae en una incoherencia y falta de lógica imperdonables (...) El triste articulista de El Mercurio comete la inocentada de reconocer todos los males que aquí existen, de reconocer la justicia que le asistirá al trabajador para quejarse, pero ipobre hombre! Nos niega el derecho a nosotros a decirlo, como si ellos solos fueran los privilegiados para la crítica de los defectos sociales (...) Dice El Mercurio que nosotros incitamos al pueblo a sacudir a sangre y fuego su dolorosa esclavitud. Ese diario nos calumnia con esa expresión y nos prueba que carece de juicio y de capacidad para juzgar los inevitables problemas sociales de la humanidad. Como la insolencia de los "grandes" periodistas es una virtud, estamos seguros que El Mercurio no tendrá un momento de honradez periodística para reconocer que ese artículo es una infamia"36

En definitiva, queda por analizar más detalladamente las formas que esta prensa utiliza para su confrontación con la prensa oficial, así como determinar con mayor precisión si su interpelación está dirigida exclusivamente a los sectores sociales de los cuales se origina o si hay en ella una convocatoria que apunte a un espacio social más ancho, entre otras interrogantes que no han sido mayormente investigadas sobre ella.

1 El presente artículo es producto del Proyecto Fondecyt N 1010016.

2 Ver OSSANDON B., Carlos y SANTA CRUZ A., Eduardo: ENTRE LAS ALAS Y EL PLOMO. La gestación de la prensa moderna en Chile. Ediciones ARCIS-DIBAM-LOM, Stgo., 2001.

3 Ver BERNEDO, Patricio y ARRIAGADA, Eduardo: Los inicios de El Mercurio de Santiago en el epistolario de Agustín Edwards Mac Clure (1899-1905). Revista HISTORIA N³5. Apartado. Instituto de Historia, Universidad Católica de Chile, Stgo., 2002.

4 SANTIVAN, Fernando: OBRAS ESCOGIDAS. Editorial Zig Zag, Santiago,1965. Pág.1599. Santiván constituye una opinión autorizada, ya que su propia trayectoria da cuenta de buena parte del proceso. Muy joven y ya iniciada su carrera literaria, se incorpora al diario católico El Porvenir, como forma de subsistencia. Luego pasa a los también católicos El Diario Popular y La Unión, a pesar de sus convicciones cercanas al Anarquismo y antes de ser una figura ya consagrada en el ambiente literario. Sólo después se integrará como figura a Zig Zag y a la colaboración con otros medios, como el radical La Razón. De alguna forma, en él se manifiesta vivencialmente la separación entre el periodista profesional y el escritor, propia de la modernización del campo cultural chileno en ese período.

5 Cit. en SILVA CASTRO, Raúl: PRENSA Y PERIOdismo EN CHILE. Ediciones U. de Chile, Stgo.,1958. Pág. 307. 6 SILVA CASTRO, Raúl: Op. Cit. Pág. 315.

7 En esa dirección, publicaba un suplemento literario llamado Los Lunes, debido a que aparecía ese día de la semana y en el cual haría sus primeras armas Augusto D' Halmar; también colaboraron en él Gonzalo Bulnes, Luis y Augusto Orrego Luco, Emilio Rodríguez Mendoza, conocido por su seudónimo A. de Gery y en este diario comenzó su carrera Carlos Varas Montero (Mont Calm).

8 RODRIGUEZ MENDOZA, Emilio: ALFREDO IRARRAZAVAL ZAÑARTU. Adición a iComo si fuera ayer!. Editorial Jurídica de Chile, Santiago., 1955. Pág. 68

9 Ver OSSANDON B., Carlos y SANTA CRUZ A., Eduardo: Op. Cit.

10 Para enfrentar dicha competencia Galvarino Gallardo Font, propietario y director desde 1890 , entregó en 1902 la dirección a su hijo, Galvarino Gallardo Nieto, con la misión de renovarlo y éste colocó al frente de la redacción al ya veterano periodista Carlos Roger. Por otra parte, intentó incorporar mayores recursos económicos por la vía de vender parte de su propiedad, con lo cual en 1902 la participación de Gallardo Font en la propiedad de la empresa no superaba el $20 \%$. Nada de eso resultó sin embargo y luego el diario fue traspasado a un grupo de empresarios encabezados por 
José P. Alessandri, los cuales, a su vez, lo cedieron a otras personas, en cuyo poder finalmente dejó de publicarse en 1911.

11 Así, por ejemplo: "Grave incidente en la Población Paris. Un transeúnte herido a sable", "Trágico suceso. El joven Francisco Prieto pone fin a sus días. Detalles" (edición del 17 de Octubre de 1910); "Sangriento drama pasional en Valparaíso", "Horrible muerte de una anciana. Por salvar una gallina perece atropellada por un tren", "Un crimen misterioso. El cadáver de una joven" (edición del 3 de Noviembre de 1910), etc.

12 Ver, por ejemplo, la edición del 9 de Diciembre de 1910 en que se publica una fotografía de cuerpo entero de la doctora señorita Eloísa Díaz, con la siguiente lectura de foto: Esta distinguida profesional fue la primera doctora que haya recibido su título en las aulas universitarias de Chile. Dicha publicación se realizaba a raíz de un homenaje que le había tributado un grupo de distinguidas señoras de nuestra sociedad. Días después, en la edición del 13 del mismo mes, se publica con tamaño de media página una fotografía del Gran Mercado de la Vega, inaugurado dos días antes y que es la actual Vega Central de Santiago.

13 Lo concreto es que el propio diario publicó un aviso en la edición del 29 de Agosto de 1911 en el cual se informaba de la disolución de la Sociedad El Ferrocarril, aunque aclarando que ello no implicaba necesariamente la desaparición del diario, ya que se esperaba que otros inversionistas se hicieran cargo de él, lo que no ocurrió, ya que en su último número aparecido el 5 de Septiembre de 1911 se publicó un llamado a remate de la citada sociedad, incluyendo el sitio, la casa (ubicada en Bandera 256), maquinarias, existencias de papel y el nombre del diario.

14 Entre esas experiencias es posible mencionar a los siguientes diarios: La República (1902-1903); El Nuevo Siglo (Junio-Octubre 1902); El Imparcial (1903-1907); Los Debates (1905-1906); La Epoca (1907-1908); La Prensa (19081910); El Día (1909-1910), entre otros.

15 Ver OSSANDON B., Carlos y SANTA CRUZ A., Eduardo: Op. Cit.

16 SANTIVAN, Fernando: OBRAS ESCOGIDAS...Op. Cit.

17 Todo lo señalado anteriormente dice relación con la prensa santiaguina. Si bien el objetivo de este trabajo no es levantar una completa cartografía de la prensa chilena en la época, sino más bien rastrear las tendencias predominantes en el desarrollo de estrategias y modelos periodísticos y en ello el peso de la prensa capitalina marcaba claramente el tono en el desarrollo del creciente mercado informativo, al menos se debe consignar la existencia de gran número de órganos periodísticos a lo largo del territorio nacional, con diarios que o tenían ya una larga data y/o tendrían posteriormente una larga existencia, incluyendo los días actuales. Entre ellos, cabe mencionar en Valparaíso al propio El Mercurio, fundado en 1827 y La Unión, fundado en 1885; en Chillán, a La Discusión, fundado en 1870; en Concepción, a El Sur, fundado en 1882; en Valdivia, a La Libertad (1876-1907) y El Correo de Valdivia, fundado en 1895; en Curicó, a La Prensa, fundado en 1898; en Punta Arenas, a El Comercio (1900-1922); en Iquique, a La Provincia (1913-1924), etc.

18 La Nación, № 1, Domingo 14 de Enero de 1917. La aparente imprecisión en las fechas dice relación con el hecho, ya remarcado en un texto citado anteriormente, acerca de las dificultades que debió sortear El Mercurio en sus primeros años. Como lo señalan los autores: "Durante sus dos primeros años de vida, El Mercurio no se diferenció mayormente de la prensa existente hasta ese entonces en Santiago y Valparaíso. De hecho, durante todo este período, el diario salió a la calle en horario vespertino, evitando así enfrentar directamente al entonces todavía poderoso e influyente matutino El Ferrocarril" (BERNEDO, Patricio y ARRIAGADA, Eduardo: Op.Cit. Pág. 17)

19 BERNEDO P., y ARRIAGADA, E.,: Op. Cit. Pág. 33.

20 SILVA CASTRO, Raúl: Op. Cit. Pág. 370.

21 SANTIVAN, Fernando: Op. Cit. Pág. 1598.

22 RODRIGUEZ MENDOZA, Emilio: Op. Cit. Pág. 87.

23 Ver MILLAR, René : LA ELECCION PRESIDENCIAL DE 1920. Editorial Universitaria, Stgo., 1981.

24 SILVA CASTRO, Raúl: Op. Cit., Pág. 379.

25 Ibid. Pág. 380.

26 En ese sentido, ejemplares analizados del año 1916 contienen denuncias contra la corrupción de la Policía y sus procedimientos, denunciando la existencia de tortura en sus cuarteles; la existencia de una Liga Militar secreta al interior de los cuarteles, adelantándose a lo que sería el complot del año 19; las deudas del Municipio de Santiago; la posibilidad de una epidemia de parálisis infantil; el impacto del salitre sintético desarrollado por Alemania; la escasez de agua en Santiago; la situación de la Universidad de Chile, a la cual se le califica de organismo caduco, etc. También merece ser destacada la publicación, a través de números sucesivos, del famoso texto de Pinochet Le Brun, Inquilinos en la hacienda de Su Excelencia, en el cual narra las condiciones que el autor califica de subhumanidad en que viven los trabajadores del fundo del entonces Presidente de la República, Juan Luis Sanfuentes y las cuales conoció disfrazado de peón que busca trabajo. 
27 Ver por ejemplo las editoriales y artículos relacionados con la Exposición Industrial verificada en la capital en Septiembre de 1916.

28 SUBERCASEAUX, Bernardo: GENEALOGIA DE LA VANGUARDIA EN CHILE. Ediciones Facultad de Filosofía y Humanidades, U. de Chile, Stgo., s/f. Pp. 84-85. A pesar de lo señalado en la cita, no ha sido posible comprobar la presencia de artículos de L.E.Recabarren en el diario. Ver CRUZAT, Ximena y DEVES, Eduardo: RECABARREN. Escritos de prensa. Nuestra América Ediciones-Terranova Editores, Stgo., 1987. Se trata de la más completa y exhaustiva recopilación de los trabajos periodísticos de Recabarren publicada en nuestro país y allí no aparece ninguna colaboración en La Razón.

29 SILVA CASTRO, Raúl: Op. Cit., Pág. 381.

30 SANTIVAN, Fernando: Op. Cit., Pág. 1599.

31 Ver OSSANDON B., Carlos y SANTA CRUZ A., Eduardo: Op. Cit.

32 Ver ARIAS ESCOBEDO, Osvaldo: LA PRENSA OBRERA EN CHILE. Edit. U. de Chile-Chillán, 1970.

33 Ibidem. Pág. 117.

34 Ver BRAVO ELIZONDO, Pedro: El Despertar de los Trabajadores, en ARAUCARIA DE CHILE. N²7, Madrid, 1984. Pp. $15-28$

35 RECABARREN, Luis E.: Trabajadores, en El Proletario, Tocopilla, 3 Diciembre 1904.

36 RECABARREN, Luis E., : Tristes mentiras, en El Despertar de los Trabajadores, Iquique, 15 Febrero 1913. 